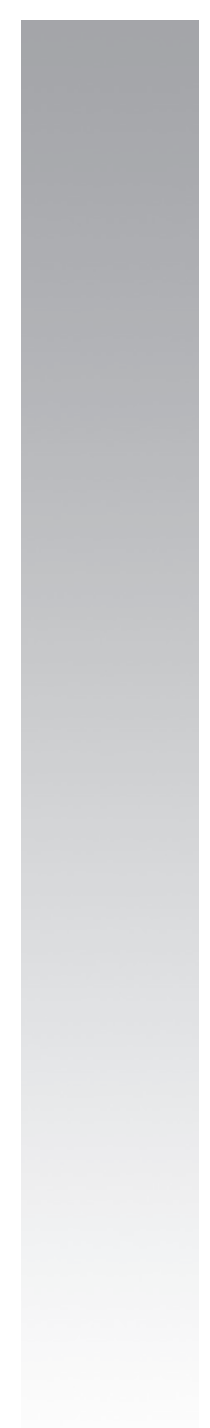

\title{
LOS FUNDAMENTOS
} METAFÍSICOS DE LA ÉTICA Y LA POLÍTICA EN

\section{LAWRENCE DeWAN:}

ELEMENTOS PARA LA CONSTRUCCIÓN DE UNA COMUNIDAD DEMOCRÁTICA, JUSTA Y PACÍFICA *

\section{Metaphysical Basis OF ETHICS AND POLITICS IN LAWRENCE DEWAN: ELEMENTS FOR THE CONSTRUCTION OF A DEMOCRATIC, JUST AND PACIFIC COMUNITY}

Este trabajo es resultado de una investigación realizada en el marco del Proyecto Foundations of Ethics and Politics in Lawrence Dewan: Elements to Build a Fair and Peaceful Democratic Community, financiado por la Embajada de Canadá en Colombia a través de un Faculty Research award (Ottawa, mayo-junio de 2009). Deseo manifestar mi total gratitud al profesor Lawrence Dewan por su generosa asistencia en esta investigación, la cual se enriqueció de manera inestimable gracias a sus iluminadoras orientaciones. Asimismo, a la Embajada de Canadá en Colombia por el amplio apoyo prestado a la financiación de esta investigación.

* Docente investigadora de la Escuela de Filosofia y Humanidades de la Universidad Sergio Arboleda, Bogotá, Colombia, donde lidera el grupo de investigación Lumen en el cual dirige el Proyecto Dewan, en español cuyo objetivo es dar a conocer al mundo de habla hispana la obra intelectual del filósofo canadiense Lawrence Dewan, O.P.

liliana.irizar@usa.edu.co 


\section{RESUMEN}

Este trabajo tiene como objetivo presentar las bases fundamentales de la ética y de la política tal como aparecen de modo reiterado en la obra de Lawrence Dewan, quien siguiendo a Tomás de Aquino, afirma que la naturaleza humana está orientada naturalmente por el Creador hacia una meta final de plenitud natural y sobrenatural. De modo que, una sociedad que pretenda instaurar estilos de convivencia democrática justos y pacíficos debe necesariamente atender a estos fundamentos metafísicos y antropológicos.

\section{Palabras clave}

Fundamentos metafísicos, ética-política, bien común, paz, Tomás de Aquino, Lawrence Dewan. 


\section{Abstract}

This article's goal is to present the foundations of Ethics and Politics in Lawrence Dewan's work. He, following Thomas Aquinas, frequently affirms that human nature is naturally oriented by the Creator towards a final target, i.e., human nature's natural and supernatural fulfillness. Thus, a society which intents to establish just and peaceful democratic styles of life, necesseraly requires to consider these metaphysical and anthropological foundations.

\section{KEY WORDS}

Metaphysical foundations, political ethics, common good, peace, Thomas Aquinas, Lawrence Dewan. 
SuMARio: PRoblema de inVestigación y Metodología; INTROducción; 1. TeOlogía natural, teleología natural y Ética natural; 2. Teleología natural humana: la SUPERIORIDAD ONTOLÓGICA DEL SER HUMANO; 3. A MODO DE CONCLUSIÓN: EL RESPETO DE LA LEY NATURAL COMO CAMINO HACIA UNA CONVIVENCIA JUSTA Y PACÍ́FICA; BIBLIOGRAFÍA.

\section{Problema de inVestigación y Metodología}

¿Cuáles son los elementos teórico-operativos que ofrecen el análisis y la reflexión metafisica de Lawrence DewAN ${ }^{1}$, con miras a la construcción de una convivencia democrática justa y pacífica? Para responder dicho interrogante se ha utilizado el método expositivo analítico y se ha recurrido, para el desarrollo argumentativo, especialmente al pensamiento metafísico de Lawrence Dewan, así como al de ARISTÓTELES y Tomás DE Aguino.

Tomando como punto de partida una bibliografia específica, recomendada por el propio autor, he procedido, en primer lugar, a analizar el planteamiento fundamental realizado por el filósofo y teólogo canadiense Lawrence DewAN. Simultáneamente mantuve diálogos regulares con él, quien fue despejando dudas, inquietudes, y esclareciendo el derrotero sistemático del presente trabajo. Finalmente, expongo de manera articulada las principales contribuciones conceptuales y prácticas para una convivencia política justa y pacífica que ofrece la metafisica de Tomás DE Aguino tal como es presentada por el profesor DEWAN. El presente artículo, resultado de investigación, recoge dichas ideas que quedan conectadas y acompasadas siguiendo el rigor de la argumentación propia del discurso filosófico.

\section{INTRODUCCIÓN}

Tal como advierte el profesor Lawrence Dewan, "la vida socio-política se funda en unas verdades que no podemos ignorar" ${ }^{2}$. Por ello, la verdad sobre el ser humano, su naturaleza y sus fines intrinsecos son de hecho temas recurrentes en la filosofia del profesor Dewan. Se trata de temas fundantes de la ética y de la filosofia de Tomás DE Aguino en general. No sorprende, entonces, que este calificado discípulo suyo repita con insistencia que "[...] la Ética tiene como su fundamento propio la

\footnotetext{
Lawrence Dewan O. P., filósofo y teólogo canadiense, es uno de los más prestigiosos representantes del tomismo actual. Posee una fecunda producción literaria, más de cien artículos sobre Metafísica y Ética. En la actualidad se desempeña como profesor de Filosofia y Teología en el Colegio Universitario Dominicano, en Ottawa, profesor adjunto del Departamento de Filosofia de la Universidad de Ottawa, y miembro de la Facultad de Estudios de Postgrado y Postdoctorales en dicha Universidad. Ha sido presidente de la American Catholic Philosophical Association y de la Canadian Maritain Association. Desde 1999 es miembro de la Academia Pontificia Santo Tomás de Aquino. En 1998 recibió de la Orden Dominicana el título honorario de Maestro en Sagrada Teología, que es el más alto galardón en Teología conferido por dicha Orden.

2 Lawrence Dewan, Comunicación personal, 28-05-09.

Nota: los textos así como las comunicaciones personales de L. Dewan han sido vertidas del inglés al español por la autora, salvo que se indique otra fuente. Igualmente sucede con el resto de citas procedentes de otros autores de lengua extranjera.
} 
consideración de la relación entre el ser humano y Dios Creador y Providente. La idea es que sin la doctrina sobre Dios, no es posible ninguna moralidad"3.

Ahora bien, el interés por presentar los fundamentos de la ética y la política en Lawrence Dewan obedece, por un lado, a que es precisamente el desconocimiento de dichas verdades por parte de quienes vienen proponiendo diversos modelos de convivencia plural y democrática lo que probablemente explique por qué tales esfuerzos teóricos no consiguen dar una respuesta de fondo a los acuciantes problemas que debilitan las democracias extendidas en diversos puntos del planeta. Por otro lado, como ha puesto de relieve J. WEST ${ }^{4}$, en algunos círculos tomistas es posible observar presentaciones "naturalistas" de la ética en tanto que separan la vida moral de Dios y del análisis metafísico de la naturaleza humana. Es lo que sucedería, por ejemplo, con J. FinNis ${ }^{5}$ y G. Grisez.

Lawrence Dewan propone, en cambio, una ética y una politica basadas en la naturaleza humana entendida como un producto de la sabiduría divina. Esto supone considerar las cosas desde el punto de vista de la causa más alta, es decir, Dios, lo cual, a su vez, implica admitir una jerarquía entre los seres creados así como reconocer el lugar destacado que ocupa el ser humano en dicha escala. De modo que, si se acepta que el orden jerárquico de los bienes es fruto de una sabiduría, de una inteligencia, resulta fácil comprender que la ética sólo puede ser una apelación a la razón y que el fundamento de la ética sólo puede consistir en el fundamento de tal llamada ${ }^{6}$.

El título de este estudio corresponde, pues, al interés por presentar las bases fundamentales de la ética y de la política tal como aparecen de manera reiterada en la obra de Lawrence DewAn, quien siguiendo a Tomás DE Aøuino afirma que la naturaleza humana está orientada naturalmente por el Creador hacia una meta final de plenitud natural y sobrenatural. De manera que, una sociedad que pretenda instaurar estilos de convivencia democrática justos y pacíficos, debe necesariamente atender a estos fundamentos metafísicos y antropológicos. Sin embargo, dichos elementos fundantes permanecen hoy, en general, olvidados o desconocidos. De hecho, advierte el profesor Dewan que:

"la necesidad de reflexionar e indagar acerca de los fundamentos de la ética, aparece cuando los principios éticos son cuestionados públicamente; algo que ha llegado a ser bastante común con tanto nihilismo contemporáneo. Pues bien, del metafísico

Lawrence Dewan, Wisdom, Law and Virtue. Essays in Thomistic Ethics, New York, Fordham University Press, 2008, p. 33.

4 Jason L. WEST, Theocentric Natural Law: Reflections on Fr. Dewan's Ethics. Conferencia inédita presentada en the Canadian Society of Christian Philosophers Session in Honor to Lawrence Dewan, Congress of the Humanities and Social Sciences, Carleton University, Ottawa, 27 de mayo de 2009.

5 Para un análisis detallado de la posición de Finnis con relación a este tema, véase L Dewan, O. P., "St. Thomas, Our Natural Lights, and the Moral Order", en Wisdom, Law and Virtue. Essays in Thomistic Ethics, Fordham University Press, 2008, cap. 12.

$6 \quad$ Cf. Lawrence Dewan, Wisdom, Law and Virtue, ob. cit., p. 33. 
es de quien se espera que defienda los verdaderos principios de las áreas particulares del conocimiento"7.

Por tanto, para quienes estamos plenamente convencidos de que tales principios existen, esto es, para quienes sabemos que "hay una filosofia pública perenne, incluso respecto de la vida humana buena y de las metas del comportamiento social, entonces, dar publicidad a esta visión, recordarla a los miembros de la sociedad, es una clara responsabilidad. La vida buena requiere promoción siquiera para preservarla de la perversidad perenne"8.

\section{TEOLOgía NATURAL, TELEOLOGÍA NATURAL Y ÉTICA NATURAL}

El profesor Dewan ofrece una concepción filosófica de la ética que, demostrada9 la existencia de Dios, sostiene que el escenario ético de la acción humana deriva de esta perspectiva teológico natural. Es, por tanto, una ética natural (distinta, aunque en armonía con la teología revelada) ${ }^{10}$, vinculada con una metafísica del orden divino de la realidad ${ }^{11}$.

Es importante remarcar que, a diferencia del camino recorrido por la teologia revelada (la cual en su discurso procede desde Dios hacia las cosas), la teología natural o filosófica parte de las cosas y desde ellas se remonta a Dios. Es el itinerario seguido, por ejemplo, en la cuarta vía ${ }^{12}$. Así, el reconocimiento de un orden de bondad observable en la realidad es anterior a la afirmación de la existencia de Dios. Pero es precisamente el descubrimiento de tal bondad ontológica lo que hace manifiesta la existencia de Dios, si por Dios entendemos lo máximo en el orden del ser, la causa del ser y la bondad, y de toda perfección en las $\operatorname{cosas}^{13}$. Bajo esta perspectiva, el profesor DewAN considera una pieza clave de la moralidad el tomar como punto de partida el orden de bondad perceptible en el mundo creado. Bondad que no debe ser entendida simplemente desde el punto de vista de la moralidad (que reconoce su principio en el obrar libre del agente racional), sino desde una perspectiva metafísica u ontológica.

En este sentido, es doctrina conocida de Tomás DE Aguino la tesis según la cual el bien y el ser son convertibles ${ }^{14}$. Hablar del ser nos remite a la ontología tomista. En ella, el Aquinate argumenta sobre el porqué de esta cuasi identidad entre el

\footnotetext{
Lawrence Dewan, Fundamentos metafisicos de la ética, ob. cit, p. 32.

Lawrence Dewan, Wisdom, Law and Virtue. Essays in Thomistic Ethics, ob. cit., p. 93.

A este respecto, Lawrence Dewan precisa que, junto con Santo Tomás, él utiliza la palabra demostración con el significado que le asigna Aristóteles en los Analíticos Posteriores, esto es, como un razonamiento que concluye en una certeza. Cfr. Lawrence Dewan, Fundamentos metafisicos de la ética, ob. cit., III.

10 Bajo este aspecto, la posición de Dewan es clara, pues sostiene que: "Si bien el verdadero bienestar de la humanidad requiere (la religión revelada), parece posible y deseable dejarla a un lado a efectos de una consideración de tipo metafisico". Lawrence DEWAN, Wisdom, Law and Virtue, ob. cit., p. 34.

11 Cfr. ibídem. p. 33

12 Cfr. Tomás De Aguino, Suma Teológica, texto latino de la edición crítica Leonina, Madrid, BAC, trad. y anotaciones por una comisión de los PP. Dominicos presidida por F. Barbado Viejo O. P., 16 vol., 1-3 (en adelante: ST).

14 Cf. Tomás De Aguino, "Cuestión disputada sobre el bien", en Opúsculos y obras selectas, Madrid, BAC, trad. y anotaciones por una comisión de los PP. Dominicos presidida por A. Osuna Fernández-Largo O. P., 2001, a.2.
} 
ser y el bien. Exponiéndolo aquí de manera resumida, decir que algo (un ente) es bueno, expresa que dicha cosa, en su existencia actual, es perfectiva y consumativa de otra. Bajo esta perspectiva se constituye en un fin (un objetivo por alcanzar) para el ente al cual perfecciona ${ }^{15}$. Se muestra, así, con claridad el significado de la conocida sentencia aristotélica: el bien es aquello que todas las cosas apetecen ${ }^{16}$. El alcance metafísico de este planteamiento no desatiende, sin embargo, el terreno de la experiencia vital en el que dicha verdad queda visiblemente constatada. De hecho, perseguimos como metas aquellas cosas que son o parecen ser buenas o convenientes para nosotros bajo algún aspecto, es decir, en la medida en que nos proporcionan algo (una perfección) que no poseemos: conocimiento, alegría, placer, compañia, entre otros ${ }^{17}$.

En sintesis, diremos con el profesor Dewan que:

“todo bien es un ser o, mejor, llamar a un ser 'bueno' no implica añadirle nada real, sino que es un modo diferente de hablar (y pensar) sobre lo mismo: el 'ser'. En realidad, el bien no difiere del ser. Con todo, añade una noción nueva a la descripción del ser. La noción que le añade es la de relación a un apetito"18.

En efecto, para Santo Tomás, que algo sea bueno significa que es apetecible, objeto de la facultad apetitiva (voluntad y apetito sensitivo). Así como decimos, por ejemplo, que son audibles las cosas objeto (de percepción) de la facultad auditiva $^{19}$. Bueno equivale, entonces, a deseable o amable por el apetito en la medida en que percibimos que tal cosa es capaz de perfeccionarnos. De ahí que, el Aquinate, avanzando en su explicación, establece que una cosa tiene el carácter de apetecible en la medida en que es perfecta, es decir, que no carece de nada de lo que pertenece a su naturaleza propia. Y esto obedece a una ley del ser ya aludida: "todas las cosas desean su propia perfección” ${ }^{20}$.

A este respecto, retomando al Aquinate ${ }^{21}$, DewAn precisará que:

"[...] una cosa es perfecta en la misma medida en que 'es actualmente', y esto es lo que nos lleva a denominar una cosa 'un ente'. Y llamamos a una cosa 'ente' cuando tiene ser (esse) [...] Por su parte, el 'esse' es la ACT-ualidad de cada realidad en absoluto. De manera que, llamar a una cosa 'un bien', lo cual es lo mismo que designarla como 'objeto de un apetito', equivale a referirse a la perfección de su ser y así a la actualidad de su ser y con ello a su acto de ser. Por tanto, decir que algo es 'un bien' es lo mismo que decir que 'es un ser', pero con la palabra 'bien' expresamos la noción 'objeto del apetito', que la palabra 'ser' no expresa”22.

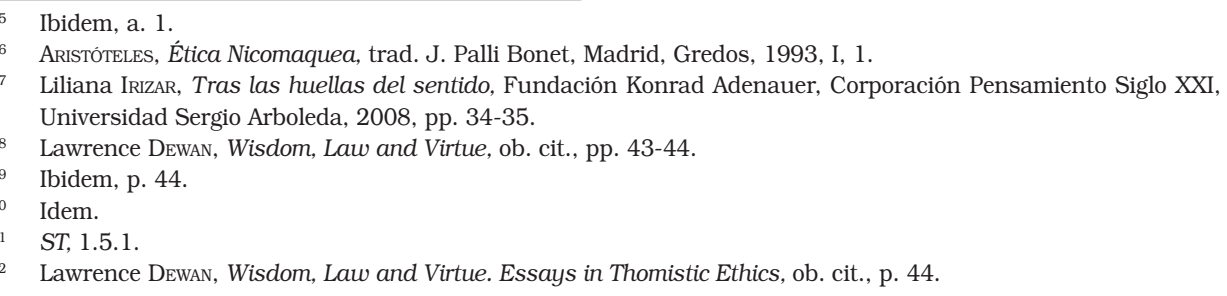

Lawrence Dewan, Wisdom, Law and Virtue. Essays in Thomistic Ethics, ob. cit., p. 44. 
Así, el orden del ser está en la base de la jerarquía de los bienes y, por tanto, define el orden del amor ${ }^{23}$. Porque, en efecto, percibimos que algunas cosas son dignas de ser amadas por sí mismas. Mientras que otras son buenas o amables en tanto que sirven o son útiles para alcanzar otras intrínsecamente valiosas. Así, "[v]emos en el ser, con anterioridad a toda intervención humana, la naturaleza de 'lo absolutamente amable' y de 'lo amable bajo cierto aspecto', esto es, el 'bonum honestum' y el 'bonum utile"'24.

En este contexto de la ontologia del bien, Lawrence Dewan se encarga de subrayar el estrecho nexo que une la noción de bien con la de naturaleza teleológica. Se trata de realidades correlativas. En efecto:

\begin{abstract}
“Esta metafísica del bien que aplica el término 'bueno' a todos los ámbitos de la realidad y no meramente al propio del ser humano, se vincula directamente con la doctrina según la cual la naturaleza es una causa que actúa por un fin. Esta doctrina, presentada por Aristóteles en la Física II, considera el apetito como algo que pertenece a todo ser en la medida que es. De ahí que, Santo Tomás generalmente incluye dentro de las inclinaciones, la 'inclinación natural' así como la 'inclinación animal' y 'la voluntad'. Y enseña que ‘de toda forma se sigue una inclinación”"25.
\end{abstract}

Como ha advertido el profesor DewAN ${ }^{26}$, reconocer el carácter teleológico de la naturaleza o, lo que es lo mismo, asumir que la naturaleza actúa por causa de un fin, es crucial para la existencia de la ética, obviamente de una no relativista, sino centrada en la verdad del ser humano y de lo que es bueno para él. Porque sólo comprendiendo la naturaleza como algo dotado de fines y tendencias intrínsecas estaremos en condiciones de entender los fines y las tendencias como algo que pertenece al ente en cuanto ente ${ }^{27}$, es decir, entenderemos, en el caso de la persona, que ella no sólo se encamina hacia el logro de objetivos libremente escogidos, sino que también posee inclinaciones naturales ordenadas hacia fines también naturales de cuyo discernimiento y consecución depende directamente su plenitud o felicidad. No sorprende, entonces, que Lawrence Dewan afirme que "la defensa de la ética pasa, consiguientemente, por la comprensión de la naturaleza y de los fines propios de las diversas naturalezas" ${ }^{28}$.

Como él mismo reconoce, se trata de un tema no exento de cuestionamientos y dificultades: "Obviamente, nos enfrentamos a una cuestión que ha generado polémicas a lo largo de los siglos. ¿Actúa la naturaleza por causa de un fin? ¿Es el acto de ver, la razón de ser del ojo y del proceso mismo por el cual es producido el ojo?" ${ }^{29} \mathrm{Y}$, en pleno acuerdo con GiLson repite con frecuencia que es la palabra "naturaleza" la que nos separa de nuestros contemporáneos ${ }^{30}$.

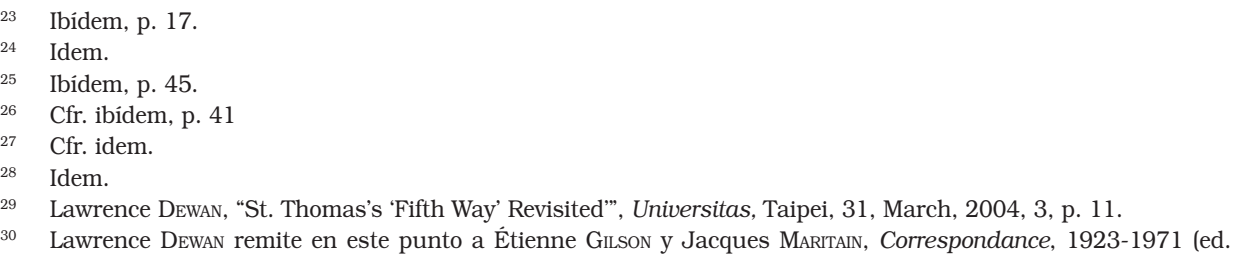


Bajo este aspecto, Lawrence DewAn anota que, puesto que para ARISTÓTELES ${ }^{31}$ es absurdo pretender probar la existencia de la naturaleza, debido a que su conocimiento es una experiencia primaria y que, por otra parte, negar que la naturaleza actúa por causa de un fin significa para el Estagirita eliminar también la naturaleza. Según esto, el profesor DewAn deduce que para ARISTóteles el principio de que la naturaleza opera por un fin es un per se notum, es decir, una verdad autoeviden$t^{32}$. De hecho, la teleología natural se hace manifiesta a través de la observación de la naturaleza. Es lo que pone de relieve Santo Tomás en diversos lugares de su obra. Citaremos aquí sólo dos pasajes considerados por DEwAN especialmente ilustrativos a propósito de este tópico.

Así, en el Comentario a la Física de Aristóteles, el Aquinate afirma que lo que más demuestra este principio es el hecho de que por las operaciones naturales algo resulta siempre de la manera mejor y más apropiada posible, como es el caso del pie que está hecho por naturaleza de tal modo que es apropiado para caminar, de ahí que si se desvia de su disposición natural no es apto para dicho uso ${ }^{33}$.

Asimismo, es bien conocida la sentencia aristotélica, ampliamente comentada por Tomás DE Aguino, según la cual, el arte imita a la naturaleza. Leamos este texto citado reiteredamente por Lawrence DEwAN:

"Como enseña ArIstóteles en el libro II de la Física, el arte imita a la naturaleza. La razón es que como se hallan entre sí los principios, así proporcionalmente se hallan las operaciones y sus efectos. El principio de lo que se hace según el arte es el intelecto humano, que según cierta similitud se deriva del intelecto divino, que es el principio de las realidades naturales. Por eso es necesario que las operaciones del arte imiten las de la naturaleza, y lo que es según el arte imite lo que es según la naturaleza. Así pues, si el maestro de algún arte hiciera alguna obra de arte, el discipulo que aprendiera el arte de él, deberá considerar la obra del maestro para obrar a su semejanza. Por eso el intelecto humano, cuya luz inteligible se deriva del intelecto divino, debe ser formado por la observación de las obras de la naturaleza, para obrar de manera similar"34.

Géry Prouvost), París, 1991, Vrin, p. 250 (letter of Gilson, septiembre 8, 1971). Gilson está hablando aquí de la "ciencia moderna": "[...] Descartes despojó de la forma sustancial a la naturaleza. Pero ya no se comprende nada más, una vez que se ha olvidado la gran palabra de Aristóteles de que no hay 'ninguna parte de un animal que sea puramente material o puramente inmaterial'. No es la palabra 'filosofia', es la palabra 'naturaleza' la que nos separa de nuestros contemporáneos. Como no espero convencerlos de la verdad (por otra parte evidente) del hilemorfismo, no creo posible proponerles nuestra hipótesis como científicamente válida". Para la frase de ARISTóteles aludida, cfr. Las partes de los animales 1.3 (643a25), Partes de los animales; trad. Elvira Jiménez Sánchez-Escariche y Almudena Alonso Miguel, Madrid, Gredos, 2000.

31 Cf. Aristóteles, Física, trad. G. de Echandía, Madrid, Gredos, 1995, II.1 (193 a2-6).

32 Lawrence Dewan, “St. Thomas's ‘Fifth Way’ Revisited”, ob. cit., p. 12.

33 "Lo que demuestra sobre todo que la naturaleza obra por algo, es que en sus operaciones algo llega a ser cuando puede existir mejor y más cómodamente; por ejemplo el pie está hecho por naturaleza de modo apto para caminar, por lo cual si se lo separa de la disposición natural no es apto para este uso, y lo mismo sucede en las demás cosas". Tomás de Aguino, Comentario a la Física de Aristóteles, trad. Celina A. Lértora, Pamplona, Eunsa, 2001, II, 12, núm. 172.

34 Tomás de Aguino, Comentario a la Política de Aristóteles, trad. de Ana Mallea, Pamplona, Eunsa, 2001, prólogo [en parte]. 
El profesor Dewan observa que en la apreciación de las acciones que realizamos en aras de un fin, es posible comprender con más nitidez qué significa que la naturaleza actúa por causa de un fin. De dichas acciones, en efecto, unas se realizan antes que otras con miras a alcanzar el objetivo:

"Supóngase que yo quiero un emparedado de jamón. Primero unto de mantequilla las tajadas de pan. Después las dejo boca arriba en un plato o bandeja; luego pongo tajadas de jamón en una de las tajadas de pan; luego pongo la otra tajada —con mantequilla - boca abajo, encima del jamón. El fin es un ensamblaje definido y cada paso del anterior al posterior, tiene una índole que está planeada para conducir al resultado final” ${ }^{35}$.

Esto es lo que identificamos como actuar por causa de un fin en nuestra vida práctica. Ahora bien,

"encontramos la misma clase de orden hacia un fin, de lo previo a lo posterior, en las cosas que suceden por naturaleza, como en el tejido de la tela de las arañas o la construcción del nido de los pájaros. Esto es tan cierto que la gente se pregunta si esas cosas son producidas por arañas o por pájaros usando sus mentes. Que esto no es así, lo atestigua el hecho de que esos seres siempre hacen las cosas de la misma manera. Como Santo Tomás dice sobre este punto: 'Pero es evidente que no obran por intelecto sino por naturaleza, porque siempre obran del mismo modo: toda golondrina hace el nido de la misma manera, y toda araña hace la telaraña de la misma forma. Esto no sucedería si obraran por entendimiento y arte, pues no todo constructor hace siempre casas iguales, porque el artífice juzga la forma concebida y puede variarla'. Tomás de Aguino, In Fis., II.13, (núm. 176)”"36.

La ciencia y la tecnología actuales, apunta DewAN, confirman con frecuencia dicho principio. Nota cómo en este sentido resultan especialmente paradigmáticas las especulaciones generadas en el ámbito científico tras el hallazgo del ofiuro ${ }^{37}$.

El debate científico contemporáneo da cuenta también de las implicaciones que supone negar o afirmar que la naturaleza actúa por un fin. Así, Lawrence Dewan ha puesto de relieve las posiciones contrapuestas del físico de partículas, Stephen

Lawrence Dewan, Fundamentos metafisicos de la ética, ob. cit, p. 64 .

Idem.

"El ofiuro, de la familia de la estrella de mar, parece ser capaz de escapar de los depredadores en las oscuras profundidades del océano, sin la ayuda de ojos. Ahora los científicos han descubierto su secreto: todo su esqueleto forma un gran ojo. Un reciente estudio muestra que la especie de estrella de mar llamada Ophiocoma wendtii posee un esqueleto con cristales que funcionan como un sistema visual, que aparentemente suministra la información que permite al animal ver el entorno y escapar del peligro. La estructura del ofiuro ha dado ideas a los científicos que quieren construir lentes pequeñitos para cosas tales como la óptica computarizada. 'Este estudio muestra cómo la naturaleza puede formar magníficos materiales los cuales superan con mucho la tecnologia actual', dijo la Dra. Joanna Aizenberg, una científica de materiales de la empresa Lucent Technologies de los Laboratorios Bell, y la directora autora del estudio. 'Ellas forman unas estructuras únicas muy interesantes que tienen notables aplicaciones mecánicas y ópticas', dijo la Dra. Aizenberg. 'Ellas forman microlentes casi perfectos.' El estudio, publicado el 23 de agosto en la revista Nature, fue liderado por un equipo internacional que incluia científicos de materiales, físicos teóricos, quimicos y biólogos". The New York Times, septiembre 4, 2001: "Una criatura sin ojos resulta ser todo ojos", por Jonathan Abraham. Citado por Lawrence DewAn en "St. Thomas and the Divinity of the Common Good", in Symposium in Honor to Russell Hittinger, Providence College, Rhode Island, 25-26 de abril de 2008 (trabajo inédito). 
WeinBerg (laureado con el premio Nóbel), con la del microbiólogo, Michael BeHE. El primero representa el punto de vista de quienes consideran que el universo es fruto del azar, mientras que el segundo expresa la posición según la cual la naturaleza revela en sus diversas manifestaciones ser el resultado de una inteligencia y de una intencionalidad ${ }^{38}$.

Ahora bien, "la negación de la teleología de la naturaleza está vinculada a la visión según la cual el universo es causado por accidente" 39 . Frente a esta mentalidad ampliamente difundida en el ámbito científico y filosófico, corresponde oponer el punto de vista de una filosofia, la de Santo Tomás e incluso la de ARISTóteles, quienes hablan desde la perspectiva de la sabiduría consumada y, por tanto, presentan la naturaleza y los esfuerzos humanos a la luz del influjo divino ${ }^{40}$. Así, "si queremos hacer nuestro, el propio punto de vista de Tomás DE Aguino, debemos advertir la importancia que reviste saber que la naturaleza es una causa que actúa por un fin. Sin esta certeza, carecemos en absoluto de toda base para la Ética, incluyendo la ética política" ${ }^{41}$. En efecto, es preciso conocer cuáles son los fines propios de la naturaleza humana con miras a descubrir cuál es el orden social más propicio para el desarrollo de la vida individual y comunitaria. Así, y tal como mostraremos más adelante, el hecho de saber que el ser humano es social por naturaleza resulta crucial para la definición teórica y operativa de la ética-politica. $\mathrm{El}$ que se escojan modelos de convivencia que potencien o, en su defecto, anulen dicha inclinación depende de que se acepte o no esta orientación fundamental de la naturaleza humana.

Sin intención de continuar ahondando en un tema en que el profesor Dewan ha escrito y continúa escribiendo con profusión y hondura, simplemente conviene subrayar algunas de sus explicaciones en torno a lo que él considera la razón más profunda de la negación de la teleología y, consiguientemente, de ese camino de

38 WeInBERg sostiene que: "Uno de los más grandes momentos en la historia del pensamiento humano fue el descubrimiento de Darwin y Wallace en el siglo XIX, según el cual ninguna 'fuerza viva' se necesita para explicar la evolución de las especies. La vida no es gobernada por leyes biológicas fundamentales independientes, sino que puede describirse como los efectos de la fisica y de la quimica, a través de billones de años de accidentes. No hace mucho tiempo que muchas creencias religiosas de los pueblos estaban basadas en el argumento de la idea (design), el argumento de que las maravillosas características de los seres vivientes posiblemente no podían haber surgido sin un plan divino. Lytton Strachey cuenta cómo el cardenal Manning llegó a la fe de esta manera. Ahora que entendemos cómo la evolución puede ocurrir a través de la selección natural de mutaciones casuales, el argumento de la idea ha perdido fuerza para quien tenga un conocimiento razonable de la ciencia biológica". Steven WeInBERG, "The Future of Science, and the Universe", The New York Review of Books, noviembre 15, 2001, citado por Lawrence Dewan en "St. Thomas and the Divinity of the Common Good", ob. cit.

Por otra parte, Michael BeHe nos dice que: "La esterilidad del Darwinismo indica que es el marco equivocado para entender la base de la vida. Una hipótesis alternativa, utilizada en mi libro como un argumento, es al mismo tiempo natural y obvia: sistemas como el del flagellum (o endamoeba coli bacterium) fueron concebidos intencionalmente por un agente inteligente. Así como en el mundo de cada día deducimos una intención cuando vemos un complejo sistema interactivo tal como una trampa de ratón, no hay razón para negar la misma conclusión a partir de los sistemas moleculares interactivos. Esta conclusión puede tener implicaciones teológicas que incomoden a muchos; no obstante, es tarea de la ciencia seguir los datos hasta donde la lleven, sin importar las molestias". Michael J. Bene, "The Sterility of Darwinism”, Boston Review, February/ March, 1997. La página Boston Review tiene una colección de artículos en esta dirección. Citado por Lawrence Dewan en "St. Thomas and the Divinity of the Common Good", ob. cit.

39 Lawrence Dewan, Fundamentos metafisicos de la ética, ob. cit., p. 5

40 Ibídem, ob. cit., VI.

${ }^{41}$ Lawrence Dewan, "St. Thomas and the Divinity of the Common Good", cit., texto inédito.

AÑo 24 - Vol. 19 Núm. 1 - Chía, Colombia - Junio 2010 
acceso a Dios (quinta vía) constituido por el reconocimiento de que las cosas están dotadas de fines intrínsecos. Esto es, la negación de que las operaciones de la naturaleza han sido pensadas y diseñadas por una inteligencia y, en última instancia, por un ser supremo en el orden de la inteligencia, esto es, Dios.

La explicación de tal rechazo, observa el profesor Dewan, "procede del fracaso en otorgar a la sustancia la primacía que le corresponde" ${ }^{2}$. De hecho, Dewan presenta la doctrina de la forma sustancial como el fundamento de la teleología natural:

"Con esto pretendo insistir en que un perro o un caballo o un gato no son meramente una reunión de partículas, sino que son más bien lo que primariamente entendemos como un ser. Es aquella clase de unidad que llamamos un 'sí mismo'. Nuestra tarea consiste, entonces, en encender una luz respecto de lo que existe 'por sí', en latín 'per se""43.

La clave del problema ha sido ofrecida por GiLson en un texto destacado frecuentemente por DEwAN:

"ARISTóteles juzgó tan evidente la finalidad en la naturaleza que se preguntó cómo sus predecesores pudieron no haber visto esto, y lo que es peor aún, que hubieran negado su presencia. A los ojos de ARISTótELEs, su error se explica porque erraron en lo concerniente a las nociones de esencia y sustancia [Partes de los Animales 1.1]. La subsiguiente historia de la filosofia debería confirmar la exactitud de este diagnóstico porque mientras la noción aristotélica de sustancia como unidad de materia y forma subsistió, aquélla de la finalidad permaneció incuestionable, pero tan pronto como en el siglo XVII BACON y DescaRTES negaron la noción de forma sustancial (forma que constituye una sustancia, por su unión con la materia), la causa final se volvió inconcebible. Por cierto, la sustancia definida por su forma es el término de la generación. Lo que quedaba, una vez excluida la forma, era la materia extensa, o más bien la extensión misma, que es el objeto de la geometría y solamente es susceptible de meras modificaciones mecánicas. Sometió a la mecánica la totalidad del dominio de los seres vivos, incluyendo Descartes el cuerpo humano. La célebre teoría cartesiana de las 'máquinas animales', que sin duda sorprendió a La Fontaine, ilustra perfectamente este punto"44.

En efecto, ignorar la forma sustancial supone ignorar lo que constituye la unidad de las unidades: lo que hace a una cosa ser lo uno que $\mathrm{es}^{45}$. Así,

"si visualizamos las cosas con las que vivimos, es decir, los humanos, los perros, los gatos, los pájaros, etc., como verdaderas unidades primarias, entonces, de cualquier modo que ellas hagan su aparición en la escena (el campo de la investigación

42 Lawrence Dewan, “St. Thomas's 'Fifth Way' Revisited”, ob. cit., p. 12. Remarca, asimismo que: “Tendriamos que comenzar con la comprensión de las cosas como sustancias, donde por 'sustancia' entendemos la cosa subsistente, la cosa que tiene su propio ser, en contraste con aquello que simplemente inhiere". Lawrence Dewan, Fundamentos metafisicos de la ética, ob. cit., p. 70.

44 Etienne Gilson, De Aristóteles a Darwin (y vuelta), trad. A. Clavería, Pamplona, Eunsa, 1980, pp. 51-52.

45 Cf. Lawrence Dewan, “St. Thomas's 'Fifth Way' Revisited”, cit. p. 13. 
biológica), su carácter télico es irreductible. Su ser exige como principio una mente. Y desde que ellas no tienen inteligencia, ellas mismas atestiguan la existencia de una mente ordenadora" ${ }^{46}$.

Si, de hecho, se aceptan esos seres que llamamos sustancias o "modos de actualidad”, es preciso admitir un modo de actualidad más elevado, es decir, Dios, que justifique la existencia de las mismas. Si, en cambio, alguien está convencido de que seres como los humanos, los perros o los gatos, son una especie de ensamblaje carente de unidad intrínseca, entonces, "la quinta vía carecerá de validez para esa persona. Sin embargo, cuanto más seriamente se considera la unidad propia de dichas cosas, más evidente llegará a ser la quinta vía, sea cual sea la doctrina de las causas intermedias que se proponga" 47 .

Las formas sustanciales, ha puesto de relieve Lawrence DewAN, son algo divino en las $\cos ^{4}{ }^{48}$, reflejos de la divina inteligencia y de la perfección de Dios. Por tanto, el hecho de que la ética que defendemos reconozca en la naturaleza sus fundamentos, obedece a que en esta filosofia metafísica la naturaleza es vista como una manifestación de la sabiduría divina. Es esto, precisamente, "lo que nos impulsa a imitar la naturaleza en nuestra búsqueda de lo que es recto. Esto sugiere que la línea de pensamiento que encontramos en la quinta vía de Santo Tomás es lo que constituye la base de nuestra moralidad" 49 .

Prestar atención a las formas sustanciales creadas conduce a la luz; luz de una inteligencia que ilumina el significado y la finalidad natural de dichos seres. Algo muy distinto de lo que sucede cuando se intenta explicar su existencia a partir del mero ensamblaje azaroso de partículas. Lo cual equivale a pretender que su generación ha tenido lugar "desde la noche o a partir de lo que es meramente potencial, tal como lo hicieron los teólogos y los científicos de la naturaleza criticados por Aristóteles" ${ }^{50}$.

Lo cierto es que esta presentación de los fundamentos metafísicos de la ética nos enseña cómo debe ser entendida la conexión entre Dios y la moralidad. Se trata de una visión de los seres creados según la cual "[n]o es sencillamente que postulemos un Dios que decreta acciones que se deben llevar a cabo y acciones que se deben evitar"51. Sino que pone de relieve la presencia de una jerarquía de bienes que nos conduce a la conclusión de que existe un ser que es la fuente de todo bien y a quien llamamos Dios. Permite, así, vincular a Dios con el orden de bien que encontramos en las cosas: "Sólo cuando vemos el lugar del ser humano dentro de

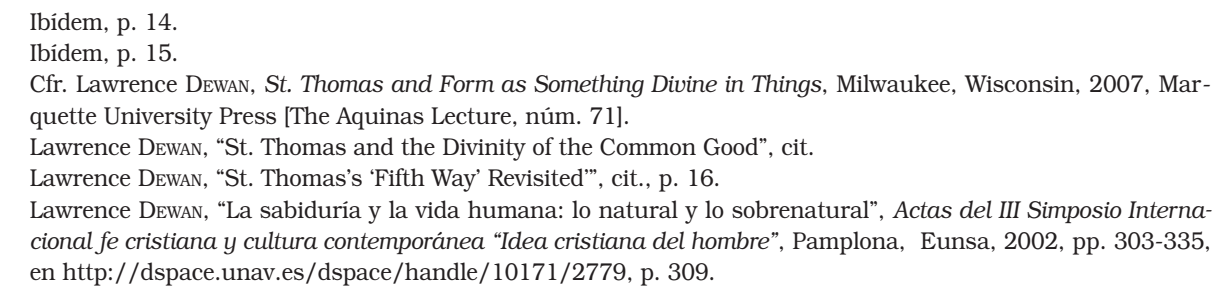


este orden y de la relación humana con Dios, llegamos a comprender de manera adecuada la moral"52.

\section{Teleología NATURAL humANa: LA SUPERIORIDAD ONTOLÓGICA DEL SER HUMANO}

"Tras haber tomado nota de la teleología que hallamos en la naturaleza, nos encontramos bien ubicados para vernos a nosotros mismos no sólo como electores, sino como nosotros mismos en cuanto tenemos una inclinación natural. Tenemos una naturaleza no sólo como parte de una realidad corpórea, sino también como seres intelectuales" ${ }^{\prime 3}$.

La ontología hilemórfica ${ }^{54}$ permite captar la naturaleza humana como unidad que abarca e integra en sí misma la dimensión material y la espiritual. Con la expresión ontologia hilemórfica, el profesor Dewan hace referencia a un modo de abordar y de conocer la realidad que tiene en cuenta sus dos componentes metafísicos esenciales: materia (hyle) y forma (morfé).

Ahora bien, los seres entendidos en términos de materia y forma reflejan la presencia de una jerarquía natural entre ellos que es fruto de la grandeza específica propia de cada uno ${ }^{55}$. Precisamente la inmaterialidad o espiritualidad del alma humana, y las operaciones espirituales de que es principio, le permiten ocupar un lugar destacado dentro de dicha escala ontológica. Pero esto que acabamos de afirmar sólo resulta patente a partir de un análisis metafísico. Tal como puntualiza DEwAN, la metafísica es necesaria para poner de manifiesto la auténtica dignidad del hombre. En efecto, descubrimos tal dignidad a partir de la ubicación del ser humano en la jerarquía de los seres. Se trata de una jerarquía que se mide "en términos de la prioridad del acto sobre la potencia, prioridad en cuanto a la nobleza, a la inteligibilidad y a la bondad" ${ }^{56}$. Prelación que resulta de la ubicación más próxima de un ente respecto de la causa del ser. Ahora bien, la mayor cercanía de la persona humana con relación a la causa primera se evidencia en que posee un alma espiritual que le permite conocer a Dios y dirigir su existencia hacia él, viviendo con él una relación de amistad:

"Con el fin de mostrar la dignidad humana fundamental de un modo apropiado, debemos localizar al ser humano en la jerarquía del ser, el cual se mide en su totalidad por su proximidad con la causa del ser en cuanto ser. Tal como afirma Santo Tomás: '[...] pues una causa es siempre superior a su efecto, y entre los efectos son superiores los más próximos a la causa ${ }^{57}$. Es por eso, sostiene el Aquinate ${ }^{58}$, que:

Ibídem, p. 310.

Lawrence Dewan, "La sabiduría y la vida humana: lo natural y lo sobrenatural", cit., p. 318.

Cfr. Lawrence Dewan, Wisdom, Law and Virtue..., ob. cit., p. 65.

Ibídem, p. 64.

Lawrence Dewan, “St. Thomas and Metaphyscial Hierarchy: Some Observations”, Conferencia leída en el 42 Congress on Medieval Studies, Kalamazoo, 2007 (inédita).

57 ST 1-2.66.1.2

58 Tomás de Aguino, In librum B. Dionysii De divinis nominibus expositio, ed. Pera, Rome\Turin, 1950, Marietti, 4.3

DÍKAION - ISSN 0120-8942 
'La bondad divina es [...] la medida de los seres porque sobre esta base es posible conocer cuánta nobleza de ser posee cada uno de los seres existentes, a saber, según su proximidad o su alejamiento de la bondad divina"59.

La nobleza del ser humano explica, a su vez, la singular y elevada relación que la une al Creador. En efecto, "la providencia divina cuida del ser humano, criatura racional, por razón de sí misma; en cambio, se ocupa de las criaturas inferiores por causa de la criatura racional" 60 .

\section{De modo que, la naturaleza humana}

"tiene un tipo de infinitud que se encuentra en relación con la realidad corpórea. Tenemos la capacidad de conocer lo que está ordenado al ser en su universalidad: 'todas las cosas'. Además, tenemos un deseo natural que es proporcional a esa capacidad universal de saber. Esta visión del ser humano - como naturaleza que tiene un fin natural, un estado perfeccionado natural o realizado- es la que controla la concepción total de la ética”"61.

El alma humana, si bien está unida al cuerpo como su forma, es esencialmente espiritual o inmaterial. Por esta razón es capaz de emanciparse totalmente de la materia haciendo partícipes de la riqueza y plenitud de su actualidad a otros entes que pasan a tener en ella una existencia totalmente espiritual o inmaterial, es decir, son captados por el alma racional en lo que ellos mismos tienen de más actual o formal: su naturaleza universal de entes. Por el conocimiento intelectual el alma conoce lo que las cosas son, es decir, conoce su esencia:

"Es importante observar que, si bien el cognoscente, por su forma, queda limitado a su propio ser, no obstante, esto no ocurre de modo tal que, por así decirlo, se cierre la puerta respecto de la recepción de las especies de otras cosas. Así, gracias a la presencia de estas especies o formas, nuestra alma posee un ser más amplio: el alma es, de alguna manera, todas las cosas. En efecto, desde que la forma es el principio del ser, es posible advertir que en este caso la forma presenta un grado más elevado, precisamente en la medida en que el ser se posee más ampliamente por parte del cognoscente. Nuevamente, deberíamos notar, entonces, que, aunque se considera que hay conocimiento en la medida en que el cognoscente posee las formas de otras cosas, con todo, el conocimiento se comprende de modo definitivo cuando se entiende como el ser del alma siendo, de alguna manera, todas las cosas"62.

(310).Y añade que: "Es posible advertir que Tomás de Aquino, en otros textos [cf. Cf. SCG 1.28], asocia nobleza con perfección, lo cual es totalmente esperable desde que él mismo asocia estrechamente la perfección con la causa agente o eficiente. 'Perfecto' es lo que puede producir algo semejante a sí [Ver ST 1.5.4, donde el Aquinate cita a Aristóteles, Meteorología 4.3 (380a12); también ST 1.4.1 sobre la perfección del agente]. Pero todas estas cosas, agencia, perfección, nobleza, se reducen a la prioridad del ser en acto respecto del ser en potencia. Es más noble lo que tiene más de aquello que conduce a ser primero (esto es, prior-idad), y esto es "ser en acto". Lawrence Dewan, "St. Thomas and Metaphyscial Hierarchy: Some Observations", cit.

59 Lawrence Dewan, Fundamentos metafisicos de la ética, ob. cit., p. 165.

60 Cf. ibídem. Dewan refiere aquí el pasaje de Suma contra gentiles, edición bilingüe dirigida por L. Robles Caicedo, O. P. y A. López Sierra, O. P., Madrid, BAC, 2007, 3.112 (En adelante: SCG).

61 Lawrence Dewan, "La sabiduría y la vida humana: lo natural y lo sobrenatural", ob. cit. p. 318.

62 Lawrence Dewan, Wisdom, Law and Virtue..., ob. cit., p. 147. 
De ahí que, cuando un alma es más cercana a la perfección del Primer Ser puede reproducir, en alguna medida, su poder creador o eficiente a través del acto de conocimiento. Por él cada alma cognoscitiva en su propio orden de perfección, a imitación del Ser "en quien preexiste todo el ser como en su causa primera", da de su actualidad a las cosas conocidas, es decir, les da el ser, aunque no real sino intencional, que es el ser que pertenece a lo conocido en cuanto que tal:

"Uno de los más claros principios de jerarquía entre las sustancias es la presencia o la ausencia de conocimiento, y particularmente de conocimiento intelectual. Tal vez, una de los mejores modos de acercarse al sujeto sea, entonces, considerar el valor del conocimiento. Se puede advertir, en efecto, que el valor del conocimiento es realmente una indicación del valor del ser y de los modos o medidas del ser”63.

De hecho, Tomás DE Aguino, ante la pregunta “¿Dios posee conocimiento?”, presenta el conocimiento relacionándolo con la perfección, es decir, con aquella plenitud del ser que él denomina inmaterialidad ${ }^{64}$.

Esta presentación esquemática en torno a la grandeza del espíritu humano permiten apreciar con mayor claridad por qué el profesor DewAn insiste en la necesidad de recurrir a la ontologia hilemórfica si se quieren superar los límites e incluso, las contradicciones encerradas en los diversos argumentos a favor de la dignidad humana. En efecto, lo que él propone, de la mano de Tomás DE Aguino, es "una visión sapiencial del hombre y de su vida"65 a partir de la cual es posible acceder a una comprensión más plena de la dignidad e incluso, de la sacralidad del ser humano.

Dicha visión metafísica pone de manifiesto que el hombre es una naturaleza dotada de una función propia que es preciso conocer al intentar descifrar el uso adecuado de la libertad que sea capaz de conducirlo a la plenitud: "Deberíamos acentuar esta visión del ser humano natural, que es la visión de nuestra propia naturaleza. De ella depende toda la ética. ¿Qué deberiamos ser nosotros?”66

Según lo expuesto, es posible apreciar que la forma sustancial propia del ser humano, es decir, su alma racional, indica cuál es su función propia, de cuya potenciación depende su felicidad o plenitud:

Lawrence Dewan, Fundamentos metafisicos de la ética, ob. cit., pp. 166-167.

64 Cfr. Idem. El profesor Dewan cita allí (p. 167) el esclarecedor pasaje de ST.1.14.1: “[...] los seres dotados de conocimiento se diferencian de los que no lo tienen en que estos últimos no poseen más que su propia forma, mientras que los primeros alcanzan a tener, además, la forma de otra cosa ya que la especie o forma de lo conocido está en el que lo conoce. Por donde se echa de ver que la naturaleza del ser que no conoce es más limitada y angosta y, en cambio, la del que conoce, es más amplia y basta [amplitudinem et extensionem]; y por esto dijo el Filósofo en De anima, 3 [431b21] que 'el alma, en cierto modo es todas las cosas'. Pues bien, lo que limita la forma es la materia, por eso hemos dicho que cuanto más inmateriales sean las formas tanto más se aproximan a una especie de infinidad. Por tanto, es indudable que la inmaterialidad de un ser es la razón de que tenga conocimiento, y a la manera como sea inmaterial es inteligente. Y por esto dice también el Filósofo en De anima 2 [424a32-b3], que las plantas no conocen, debido a su materialidad; pero el sentido es ya apto para conocer, porque recibe especies [specierum] sin materia, y el entendimiento lo es mucho más, porque está más separado de la materia y menos 'revuelto' con ella, como se dice en el libro De anima 3 [429a18]. Por consiguiente, puesto que Dios, según hemos dicho [1.7.1], está en la cúspide de la inmaterialidad, tiene también el grado supremo de conocimiento".

65 Lawrence Dewan, Wisdom, Law and Virtue. Essays in Thomistic Ethics, ob. cit., p. 332.

66 Lawrence DewAN, "La sabiduria y la vida humana: lo natural y lo sobrenatural”, cit., p. 326. 


\begin{abstract}
"Aristóteles establece claramente que la naturaleza humana ('la función del hombre') ${ }^{67}$ es la clave de la verdadera moralidad. Es necesario tener una concepción de la meta de la vida humana; existe la concepción de la virtud como una formación de la persona con el objetivo de hacer que la vida de la razón no sólo resulte aceptable, sino algo de lo que se pueda disfrutar. Y, en todas sus demás obras, Aristóteles define claramente lo que él percibe como la meta del deseo humano: '[...] cada ser humano, por naturaleza, desea saber', lo que en última instancia significa: desea conocer la más elevada causa" ${ }^{\prime \prime}$.
\end{abstract}

DEwAN, en plena sintonía con el Estagirita, remarca que "al identificar la razón como lo propio del hombre logramos identificar la felicidad como una operación de acuerdo con la virtud perfecta"69. La naturaleza intelectual o espiritual del alma humana indica que la actividad que realiza plenamente al ser humano, incluso en la vida presente, es la contemplación, es decir, "la actividad del hombre más semejante a la actividad divina"70. Y la mayor plenitud obviamente acaece al contemplar el objeto de la razón más perfecto: $\operatorname{Dios}^{71}$.

Santo Tomás DE Aguino desarrolló este tema de la plenitud humana con mayor amplitud pero moviéndose siempre en la misma dirección que ARISTÓTELES:

"Como escribe el Damasceno, el hombre se dice hecho a imagen de Dios, en cuanto que la imagen significa 'un ser intelectual, con libre albedrio y potestad propia'. Por esto, después de haber tratado del ejemplar, a saber de Dios, y de las cosas que el poder divino produjo según su voluntad, resta que estudiemos su imagen, que es el hombre en cuanto es principio de sus obras por estar dotado de libre albedrío y dominio sobre sus actos"72.

En este texto, comenta el profesor Dewan, "a la vez que se considera el "movimiento’ u operación de la criatura racional, se nos muestra que el interés propiamente

67 ARISTóteles, Ética de Nicómaco, ob. cit., 1.7 (1097b22-25): "Decir que la felicidad es lo mejor parece ser algo unánimemente reconocido, pero, con todo, es deseable exponer aún con más claridad lo que. Acaso, se conseguiría esto si se lograra captar la función del hombre".

Tomás DE Aguino comenta: “[Aristóteles] muestra que hay alguna operación propia del hombre [...]. Primero, por lo que acaece al hombre. Ocurre que el hombre puede ser tejedor, curtidor, gramático, músico o algo similar. Ninguna de esas actividades hay que no tenga una operación propia. De otra manera, se seguiría que al hombre le advendrian ociosa e inútilmente. Si lo que es según la naturaleza, que está ordenado por la razón divina, es ocioso e inútil, es mucho más desatinado a que lo sea según el arte, que está ordenado por la razón humana. Por tanto, como el hombre es algo que existe según la naturaleza, es imposible que pueda ser naturalmente ocioso, como si no tuviese una operación propia. Luego, hay alguna operación propia del hombre, como de aquello que le acaece. Cuya causa es porque cada realidad, tanto natural como artificial, es por alguna forma, la cual es principio de alguna operación. Por ende, como cada realidad tiene un ser propio [proprium esse] por su forma, así también tiene una operación propia”. Tomás de Aguino, Comentario de la Ética a Nicómaco de Aristóteles, trad. A. Mallea, Pamplona, Eunsa, 2001, I. 10 (núm. 68-69).

68 Lawrence Dewan, "La sabiduría y la vida humana: lo natural y lo sobrenatural”, cit., p. 307.

69 Lawrence Dewan, "St. Thomas and the Divinity of the Common Good", ob. cit.

70 Lawrence Dewan, Fundamentos metafisicos de la ética, ob. cit., p. 28, nota 8. Se refiere al siguiente pasaje de la Ética a Nicómaco: “[...] aquellos a quienes la contemplación pertenece en un grado más alto, son más plenamente felices [...]" (1187b30).

71 Cf. ARIstóteles, Metafisica, trad. T. Calvo Martínez, Madrid, Gredos, 1994, 1.1-2 (980a23-ff.), 4.1 (1003a17-32); 12.7 (1072b13-29); 12.10 (1076a3-4).

72 ST, 1-2. prólogo.

Año 24 - Vol. 19 Núm. 1 - ChíA, Colombia - Junio 2010 
teológico en el agente humano libre radica en su "ser como-Dios"'73. La grandeza del ser humano y la sublimidad de las metas que está llamado a alcanzar tanto en el nivel individual como en el social, sólo pueden captarse cabalmente a partir de su ser imagen de Dios:

"En ST, 1.93.4, acerca de que la imagen de Dios se encuentra en todo ser humano, Tomás de Aquino enseña que el hombre es el ser más semejante a Dios en la medida en que puede más que nadie imitar a Dios; y la naturaleza intelectual imita a Dios principalmente respecto del conocimiento y amor que Dios se tiene a sí mismo"74.

Sin embargo, aunque es muy importante resaltar la dignidad del alma espiritual del ser humano, es preciso también remarcar la dignidad del cuerpo. Para evitar caer en el dualismo, tal como sucede en la filosofia cartesiana ${ }^{75}$, conviene hacer énfasis en la unidad esencial del compuesto hilemórfico que es el hombre. El alma espiritual, al unirse al cuerpo (materia) como forma suya, le transmite su estatus ontológico, esto es, lo humaniza, y, por tanto, lo dignifica. En el hombre todo es humano, lo cual es tanto como afirmar que en el hombre todo queda espiritualizado y sublimado ${ }^{76}$ en virtud de su forma o alma racional:

"Lo que estoy procurando poner de relieve es la unidad del ser humano, cuerpo y alma, incluso cuando se enfatiza la espiritualidad, la inmaterialidad del alma humana. Nos encontramos muy lejos del 'dualismo' de un Descartes o de un Platón. Esto se evidencia en la enseñanza según la cual el alma humana, por sí misma, no es una persona. Se podría pensar que la clásica definición de persona como 'sustancia individual de naturaleza racional' se ajustaría al alma humana. El alma humana, de hecho, es un individuo y puede sobrevivir a la muerte del compuesto; además, su racionalidad es evidente. Pero la noción de alma no logra abarcar el contenido expresado en la palabra 'naturaleza'. La primera carece del carácter de acabamiento significado por la palabra naturaleza ${ }^{77}$. El tipo de unidad completa y coherente significado por una "natu-

Lawrence Dewan, Fundamentos metafisicos de la ética, ob. cit., p. 30.

Idem. Alli mismo el profesor Dewan anota a pie de página (núm.12) el siguiente comentario: "Según esto, Santo Tomás ve tres niveles de la "imagen de Dios" en el hombre. Así, leemos: 'De ahí que la imagen de Dios en el hombre puede ser considerada de tres modos. 1) Primero, en cuanto que el hombre posee una aptitud natural para conocer [intelligendum] y amar a Dios, capacidad que consiste en la naturaleza propia de la mente que es común a todos los hombres. 2) Segundo, en cuanto que el hombre conoce y ama actual o habitualmente a Dios, pero de un modo imperfecto; ésta es la imagen procedente de la conformidad por la gracia. 3) Tercero, en cuanto que el hombre conoce y ama actualmente a Dios de un modo perfecto; ésta es la imagen que resulta de la semejanza de la gloria [...]'. El nivel natural, que se encuentra en todo ser humano, se relaciona igualmente con la naturaleza de la criatura intelectual que es de tal condición que puede ser elevada por la gracia (cf. ST, 1.12.4. ad 3). Sin embargo, cabe tener en cuenta 1-2.109.3, donde se nos dice que en el estado de la naturaleza integra, anterior a la caída, el hombre era capaz de amar a Dios más que a sí mismo sin la ayuda del don de la gracia sobreañadido a la bondad natural (si bien esto hace referencia al amor de Dios como autor de la naturaleza y no a la sociedad espiritual con Dios fruto de la caridad. Cf. 1-2.109.3. ad 1)".

75 Cf. Lawrence Dewan, Wisdom, Law and Virtue. Essays in Thomistic Ethics, ob. cit., p. 61.

76 Cf. ibídem, p. 62.

77 ST 1.75.4. ad 2: "[...] no toda sustancia individual es hipóstasis o persona, sino la que posee naturaleza específica completa. Por eso no pueden ser llamadas 'hipóstasis' o 'personas' la mano o el pie, ni tampoco el alma, que es una parte de la especie humana. sino aquella que tiene la naturaleza completa de la especie [speciei]".

Y 1.29.1.ad 5: "Debe decirse que el alma es una parte de la especifica naturaleza humana [speciei] y por lo tanto, aunque es separada [después de la muerte], porque sin embargo retiene la naturaleza de unidad [para el cuerpo], no puede llamarse la 'sustancia individual' que es la hipóstasis o sustancia primera; asi como tampoco [puede] 
raleza humana' es la de tal alma perfeccionando tal cuerpo ${ }^{78}$. Así, la resurrección del cuerpo señala la restauración de la persona a la existencia. Efectivamente, lejos de disminuir la unidad del ser humano, la nobleza del alma entraña mayor unidad en el ser humano que en otras sustancias corpóreas"79.

La visión sapiencial o metafísica del ser humano nos enseña, por tanto, que sólo redescubriendo la excelsa naturaleza de su ser es como el hombre puede reencontrarse a sí mismo y, consiguientemente, encontrar vias para la construcción de relaciones justas, pacíficas e incluso de amistad cívica con los demás. En suma, caminos que lo conduzcan a la plenificación de su ser. Sin esta visión, resulta obvio que dificilmente las líneas de acción política, los programas educativos y, en general, las leyes puedan responder de manera satisfactoria a las exigencias que derivan de la grandeza ontológica del ser humano ${ }^{80}$.

\section{EL RESPETO DE LA LEY NATURAL COMO CAMINO HACIA UNA CONVIVENCIA JUSTA Y PACÍFICA}

Llegamos así a otro elemento fundante de la vida ético-politica con el cual daremos por finalizado este estudio. Es el tema de la ley natural como vía obligada que el ser humano y la sociedad deben recorrer a fin de encontrar estilos vida de personal y comunitaria verdaderamente humanos. Porque, "la vida humana es una vida social, y la ley es uno de sus rasgos más esenciales. La ley constituye, en efecto, el ordenamiento racional de dicha vida" ${ }^{81}$.

Toda ley es "ordenación racional" en la medida en que toda ley tiene origen divino, es decir, su fuente es la sabiduría divina:

"Que toda ley tiene un origen divino es una doctrina que no es dificil de encontrar en los escritos de Santo Tomás de Aquino. En ST 1-2. 93.3 el planteamiento explícito es que toda ley deriva de la ley eterna, la ley eterna que ha sido explicada como "la razón de la divina sabiduría en cuanto dirige todos los actos y movimientos"”2.

Es importante remarcar el especial acento que ha puesto Lawrence DewAn en subrayar el origen divino de la ley, refiriéndose de modo particular a la ley natural. Bajo este aspecto ha sostenido que, en modo alguno, el calificativo de natural remite en Santo Tomás a una visión "naturalista" de dicha ley. En tanto que "[...] la naturaleza es una expresión de la sabiduría divina" ${ }^{83} \mathrm{y}$, teniendo en cuenta que toda la doctrina moral de Tomás DE Aguino descansa sobre la doctrina de que la naturaleza

hacerlo una mano o cualquier otra de las partes del ser humano. Y así ni la definición, ni el nombre: 'persona' le es adecuada".

78 Cf. ST 1.75.4; y 1.75.7.ad 3.

79 Lawrence Dewan, Fundamentos metafisicos de la ética, ob. cit., pp. 162-163.

80 Cf. Liliana IrIZAR, Tras las huellas del sentido. Sabiduría y felicidad en Lawrence Dewan, ob. cit., especialmente caps. II y III.

81 Lawrence Dewan, “The Divine Origine of Law”, Civilizar, 8 (2008) 15, pp. 123-134, p. 124. Se puede leer la versión en español de dicho artículo en Lawrence Dewan, Fundamentos metafisicos de la ética, ob. cit., V, pp. 135-152.

82 Idem.

83 Lawrence Dewan, Wisdom, Law and Virtue. Essays in Thomistic Ethics, ob. cit., p. 246. 
es una causa que actúa por un fin, tomando el término naturaleza en el sentido metafísico, es fácil concluir que el contenido moral expresado en dicha ley es, por supuesto, trascendente. Esto es, trasciende la naturaleza en el sentido de la Fisica de ARISTÓTEles: "Así, aún para la pura moral natural, de acuerdo con Tomás DE Aguino, permanece siempre la visión del agente moral como alguien en relación social con Dios, una relación que trasciende el modo de participación en lo divino que pertenece a la naturaleza subracional" 84 .

El profesor Dewan explicita cómo a partir de la lectura de los textos de Tomás DE Aguino resulta inequívoco el carácter divino de la ley natural:

"En la 1-2, la cual constituye la descripción más resumida de todo el orden moral, comienza con la beatitud (felicidad), es decir, el último fin de la vida humana, considerándola como algo cuyo logro depende en gran medida de la acción humana ${ }^{85}$. Luego se ocupa de dicha acción y de sus principios; de los intrínsecos al agente humano, como las virtudes, y termina con los principios extrinsecos, principalmente Dios. Así presentado, Dios es visto como guía, en virtud de la ley y como sostén, en razón de la gracia ${ }^{86}$. De modo que, la ley es considerada como un influjo divino. Se podría pensar que tal ayuda consiste simplemente en una clase especial de ley, la ley 'divina' especialmente revelada a nosotros por Dios. Con todo, tal como 1-2 desarrolla cuidadosamente el panorama causal general, uno observa que 'la ley' designa una realidad que se da según un orden de prioridad y posterioridad, que fluye del intelecto y voluntad divinos y que, donde quiera que se le encuentre, efectivamente permanece como una participación racional en aquella realidad divina" ${ }^{87}$.

A esta comprensión de la ley natural como algo que pertenece a los humanos y es propia de las sustancias racionales o intelectuales ${ }^{88}$ y que sólo puede ser entendida en el contexto de sus fundamentos metafísicos, Dewan la denomina "visión sapiencial de la ley" ${ }^{\text {. }}$. Haremos aquí una breve presentación de la ley natural bajo esta perspectiva sapiencial.

En cuanto a la esencia o naturaleza de la ley en general, Santo Tomás la define como: “[...] una prescripción de la razón, en orden al bien común, promulgada por aquel que tiene el cuidado de la comunidad" 90 .

84 Ibídem, p. 252. Estas observaciones han sido expuestas por DEwAN a propósito de su crítica respecto de la posición de Jean PORTER contenida en su libro Natural and Divine Law.

85 ST 1-2.5.7.

86 ST 1-2.90, prólogo; la distinción entre ley y gracia, guía y sostén, no es algo rígido: lo que constituye más verdaderamente la Ley Nueva es la gracia del Espíritu Santo: 1-2.106.1. -Dios es extrínseco a la realidad creada al modo como la causa eficiente es distinta del efecto; Dios está de tal modo presente en cada criatura debido a que es lo más profundamente intimo a ellas en virtud de la naturaleza de su efecto propio, el acto de ser; se puede afirmar, así, que su inmanencia fluye de su trascendencia. Cfr. ST 1.8.1 in toto.

87 Lawrence Dewan, "The Divine Origine of Law", cit., pp. 124-125.

88 Sobre este punto precisa que: "ley' se dice de lo no-racional sólo por semejanza; si el término se toma demasiado literalmente, la expresión 'las leyes del mundo físico' equivaldría a un antropomorfismo", cfr. ST 1-2. 91.2. ad 3.

89 Cfr. Lawrence Dewan, "The Divine Origine of Law”, ob. cit., p. 124.

90 ST 1-2.90. 4. 
Es bien conocida su clasificación de la ley en: ley eterna, ley natural, ley humana, y leyes divinas reveladas ${ }^{91}$. Tal como observa Dewan:

"La ley natural es presentada como la participación de la criatura racional en la ley eterna $^{92}$. La ley natural recibe con propiedad el nombre de ley, algo que no puede decirse de la participación de la ley eterna por parte de las criaturas inferiores no racionales. La ley natural es propiamente ley debido a que el ser humano participa en la providencia como alguien que racionalmente, en alguna medida, vela por sí mismo ${ }^{93}$. Nosotros no somos, desde luego la fuente de la legislación; antes bien, la ley está en nosotros como en alguien que es regido y medido por ella" ${ }^{\text {. }}$.

Se plantea, así, el tema de la captación de la ley natural por parte del ser humano: "La ley natural es poseída por el ser humano principalmente a través de la visión de la bondad, una visión que aparece en nuestra inmediata relación con la causa universal del ser y de la bondad"95. De hecho, la sola luz del entendimiento que capta el orden de razonabilidad y bondad en las cosas es identificada por Tomás DE Aguino con la ley natural ${ }^{96}$.

De modo especial quisiéramos remarcar aquí lo que constituye el rasgo esencial de la ley natural: "Lo que es fundamental en la presentación de la ley en Santo Tomás es su índole racional, es decir, una expresión de la razón ${ }^{97}$. La captación de lo razonable es una fuente de obligación ante nosotros" ${ }^{\prime 2}$. La ley natural posee,

ST 1-2.91 in toto.

ST 1-2.91.2.

93 ST 1-2.91.2.ad 3. "Pero las criaturas irracionales no participan de este modo en la ley eterna; por eso sólo puede denominarse 'ley' por cierta semejanza”.

$94 \quad$ ST 1-2.91.2.

95 Lawrence Dewan, “The Divine Origine of Law", ob. cit., pp. 125-126. Sin embargo, Dewan subraya que el modo natural de conocimiento del contenido de esta ley, "es el resultado de la abstracción a partir de la experiencia sensible, no algo innato; la luz intelectual o intelecto agente, aún en lo que se refiere a las primeras nociones y las verdades primeras, debe obtener la información a partir de las cosas sensibles: cf. QD. De anima 5, De Veritate 11.1, Quodlibet 10.4.1”'. Ibídem, nota 8.

96 Es lo que leemos, apunta Lawrence Dewan, en un sermón pronunciado por Santo Tomás en la Cuaresma de 1273, titulado Collationes de decem praeceptis, y algunas veces De duabus praeceptis caritatis et decem legis praeceptis: "[...] lex naturae; et haec nihil aliud est nisi lumen intellectus insitum nobis a deo, per quod cognoscimus quid agendum et quid vitandum. Hoc lumen et hanc legem dedit deus homini in creatione" ("la ley de la naturaleza; y ésta no es más que la luz del intelecto puesta en nosotros por Dios, a través del cual sabemos qué hay que hacer y qué hay que evitar. Dios, al crearlo, dio esta luz al hombre [a él]").

DewAn puntualiza, además, que "la luz del intelecto que se menciona aquí debe ser identificada con el intelecto agente que vemos en un pasaje tal como el siguiente, las Cuestiones disputadas sobre las criaturas espirituales 10 [una obra fechada en 1267 en Roma, conforme al editor de la edición Leonina, B-C Bazan]: '[...] decimos que la luz del entendimiento agente, de que habla Aristóteles, ha sido impresa inmediatamente en nosotros por Dios, y con ella nosotros discernimos lo verdadero de lo falso, y el bien del mal. A este propósito dice el Salmo 4, 6-7: Muchos dicen: ¿quién nos mostrará el bien? La luz de tu rostro ha sido grabada sobre nosotros, Señor, es decir, lo que nos muestra el bien. Así pues, lo que produce en nosotros inteligibles en acto al modo de luz participada es algo del alma y se multiplica según la multiplicación de las almas y de los hombres [...]”. Santo Tomás DE Aguino, "Cuestión disputada sobre las criaturas espirituales", en A. Osuna Fernández-Lago (coord.), Opúsculos y cuestiones selectas, Madrid, BAC, 2001, a. 10"; "The Divine Origine of Law", cit., nota 8.

97 ST 1-2.90.1.

98 La razón como ordenación hacia el fin es aquí el principio de obligación, cfr. ST 1-2.90.1 y 1-2.99.1. Para Dewan, lo fundamental es el conocimiento, la captación de lo razonable, que va acompañado de la fidelidad de la inclinación. En este punto difiere del análisis de Jacques MARITAIn, quien afirmaba que dicho conocimiento no es conceptual, sino más bien "por inclinación". Al respecto, Lawrence Dewan comenta: “No creo que este sea el punto de vista de Santo Tomás como tampoco la verdad del asunto. Tomás de Aquino, en efecto, es muy constante en 
en efecto, unas pautas comunes, unas orientaciones de base, proyectables sobre toda existencia humana puesto que radican en la naturaleza teleológica racional:

"Somos seres autoperfectibles. Somos autocultivadores de nosotros mismos. Esto significa que, no solamente hay en nosotros el terreno perfeccionable, sino también el principio activo para dicho cultivo. Somos agentes, y no meramente pacientes, de nuestra perfección. Y nuestra capacidad para ser agentes en este campo, radica en el hecho de que poseemos, como algo dado naturalmente, los principios de nuestro propio desarrollo" 99 .

Los preceptos de la ley natural son algunos de esos principios, puesto que son auténticas semillas, gérmenes de autoperfeccionamiento personal enraizados en la naturaleza humana ${ }^{100}$. En efecto, por ley natural podemos entender la "voz axiomática" de la razón natural ${ }^{101}$ acompañada siempre de la inclinación respectiva, que nos incita a buscar el bien racional, es decir, aquello que conduce a la perfección de nuestra naturaleza.

Existe un principio regulador de la naturaleza humana que es absolutamente primero: "el bien ha de hacerse y el mal evitarse". De él se derivan todos los demás, de los cuales unos se corresponden con inclinaciones comunes a los demás seres (la inclinación a conservar la propia existencia y la de la especie, y el cuidado de los hijos). Pero explica Tomás de Aguino que, además,

"[...] hay en el hombre una inclinación al bien correspondiente a la naturaleza racional, que es la suya propia, como es, por ejemplo, la inclinación natural a buscar la verdad acerca de Dios y a vivir en sociedad. Y, según esto, pertenece a la ley natural todo lo que atañe a esta inclinación, como evitar la ignorancia, respetar a los conciudadanos y todo lo demás relacionado con esto" ${ }^{102}$.

Asimismo, explicita más adelante que:

“[...] pertenece a la ley natural todo aquello a lo que el hombre se siente inclinado por naturaleza. Mas, todos los seres se sienten naturalmente inclinados a realizar las operaciones que les corresponden en consonancia con su forma; por ejemplo, el fuego se inclina por naturaleza a calentar. Y como la forma propia del hombre es el alma racional, todo hombre se siente naturalmente inclinado a obrar de acuerdo con la razón. Y esto es obrar virtuosamente. Por consiguiente, así considerados, todos los actos de las virtudes caen bajo la ley natural, puesto que a cada uno la propia razón le impulsa por naturaleza a obrar virtuosamente"103.

su presentación de la inclinación como algo que sigue al conocimiento, y de la inclinación natural como lo que sigue al conocimiento natural" (Comunicación personal, 4-06-09). Cfr. "Jacques Maritain and the Philosophy of Co-operation”, en M. Gourgues y G. D. Mailhiot (eds.), Alterité. Vivre ensemble differents, Montral, Paris, 1986, Bellarmin/Cerf, 109-117; publicado como cap. 13 en Lawrence Dewan, Wisdom, Law and Virtue..., ob. cit.

99 Ibídem, p. 201

100 Ibídem, p. 207

101 Ibídem, p. 209.

102 ST, 1-2.94.3.

103 Idem. 
A propósito de los textos que acabamos de citar, Lawrence DewAn ha subrayado dos aspectos de la ley natural que son cruciales para el tema del presente estudio: la inclinación natural de todo hombre a vivir en sociedad así como la tendencia, inseparable de la anterior, a preferir el bien común antes que el bien particular ${ }^{104}$.

A diferencia de Finnis, Lawrence Dewan enfatiza que la comunidad politica y el fin de ella - el bien común- no son meros instrumentos para alcanzar otros bienes. Es decir, la sociedad política no es un simple remedio contra el mal implicado en el obrar humano, sino que posee su bondad propia, es un bien en sí misma ${ }^{105}$.

De hecho, observa Dewan, que esto es así quedaría confirmado por el lugar privilegiado que Santo Tomás confiere a la justicia legal. Se trata de una virtud que ordena los actos de todas las virtudes hacia su fin propio, el bien común. Según esto, hay una inclinación natural a vivir en sociedad que se perfecciona a través de la virtud de la justicia legal ${ }^{106}$. Y "[e]s precisamente el bien común, del que la ley se ocupa, lo que hace a la justicia legal incuestionablemente más noble"107.

No es posible enfatizar suficientemente la relevancia y la actualidad de las reflexiones de Lawrence DewAn en torno a las inclinaciones propias de la naturaleza humana y, por tanto, acordes con la racionalidad. Es indudable que uno de los mayores males que socava a las sociedades contemporáneas es el individualismo sistemático, fuente de muchos problemas tales como la corrupción política y la violencia. Me parece que la vida en sociedad, vivida como lo pide nuestro ser más profundo, es decir, ajustando las decisiones personales a la praxis de las virtudes éticas y, por lo mismo, orientándolas hacia el bien común, ofrece soluciones de fondo a dichos problemas.

El profesor Dewan destaca que Tomás dE Aguino reitera de manera insistente en su obra en esta preeminencia del bien común sobre el bien particular. En esto, también el fundamento más profundo resulta ser el principio según el cual "el arte imita a la naturaleza”. Tomás DE Aguino recurre a dicho principio para explicar el desarrollo de las instituciones humanas:

"La naturaleza procede en su operación de lo simple a lo compuesto. Así en lo que se hace por el operar de la naturaleza, lo más compuesto es lo perfecto; es el todo y es fin de lo demás, como es evidente en cada todo con respecto a sus partes. De ahí que también la razón humana operativa procede de lo simple a lo compuesto, como de lo imperfecto a lo perfecto" 108 .

"Esto es cierto incluso con relación al ordenamiento humano ${ }^{109}$ : [...] como cuando ordena a muchos hombres en alguna comunidad. En esas comunidades que son diversas en grado y en orden, la última es la comunidad de la ciudad, ordenada a la suficiencia por si de la vida humana. De ahí que entre todas las comunidades

104 Cabe destacar que el profesor Dewan se ha ocupado del tema en el contexto de una discusión con John FinNis y las interpretaciones ofrecidas por dicho autor en esta materia. Vease St. Thomas, John Finnis, and the Political Good, cap. 17, en Lawrence Dewan, Wisdom..., ob. cit.

105 Cfr. ibídem, p. 290.

106 Cfr. ibídem, p. 293.

107 Ibídem, p. 308. Allí hace especial referencia a ST 2-2.58.12.

108 Ibídem, parágrafo 3.

109 Lawrence Dewan, "St. Thomas and the Divinity of the Common Good", cit.

Año 24 - Vol. 19 Núm. 1 - ChíA, Colombia - Junio 2010 
humanas la ciudad es la más perfecta. Como lo que cae bajo el uso del hombre se ordena a éste como a su fin, que es el fin principal con respecto a lo que es para el fin, es necesario, por eso, que este todo que es la ciudad sea el principal con respecto a cualquiera de los todos que pueden conocerse y constituirse por la razón humana" ${ }^{110}$.

Son muchos los pasajes citados por Dewan en los cuales se propone mostrar cómo Tomás DE Aguino apela a la naturaleza para justificar la primacía del bien común, en particular para el ser humano.

"En dicha justificación siempre se presenta al ser humano como una parte ${ }^{111}$ de la sociedad, junto con el argumento de que la existencia de la parte revela que su ser es por causa del todo, especialmente en el sacrificio de sí misma para el bienestar colectivo: la mano detiene la lanzada dirigida hacia la cabeza. En este sentido considérese Quodlibetales 1.4.3"112.

Sin embargo, esta afirmación de la primacía de lo común sobre lo individual, de la sociedad política sobre el individuo e incluso sobre la familia ${ }^{113}$, no debe hacer perder de vista que, para Tomás DE Aguino, "[e]l orden politico no es lo mejor en el hombre. Lo politico es 'instrumento' relativo al orden contemplativo, y las virtudes intelectuales son más nobles que las morales, la sabiduría es más noble que la prudencia política"114.

En efecto, Dewan subraya que existe una jerarquía entre el bien común político y los diversos bienes comunes, pertenecientes a los distintos tipos de comunidades que integran la comunidad politica, como es el caso de la familia. Pero todos ellos, incluido el bien común político, se subordinan al bien común del universo, es decir, a Dios $^{115}$. Esto significa, que todo orden politico se justifica y legitima únicamente

110 Ibídem, parágrafo 4.

111 "La sociedad - precisa Dewan—, es, por supuesto, una unidad de orden, no una unidad sustancial" (comunicación personal, 4-06-09). Cfr. In en prólogo, líneas 78-81 de la edición Leonina

112 L. Dewan, "St.Thomas and the Divinity of the Common Good", cit. Dewan recomienda que se lean también ST 1.60, ST 2-2.31.3, ST 2-2.31.3, ad. 2, ST 2-2.50.4 y ST 2-2.50.4. ad. 2.

113 Dewan pone de relieve que la familia es vista por Tomás DE Aguino como una parte de la sociedad política y, por tanto, debe estar orientada hacia la comunidad. De hecho, observa Dewan, "una vida familiar saludable depende de una comunidad política saludable, el bien de la familia depende del bien común político" (Comunicación personal, 4-06-09). Es fácil comprender la posición del profesor Dewan si se admite que la crisis de la familia es precisamente el resultado de los embates que ha venido sufriendo por parte de una vida social penetrada de individualismo, materialismo y hedonismo consumista, entre otras tendencias diluyentes.

114 Lawrence Dewan, "St. Thomas, John Finnis, and the Political Good", en Wisdom, Law and Virtue..., ob. cit., p. 309. Hace referencia a ST 2-2.1.66.5 ad 1 y ad 2.

115 Lawrence Dewan, "St. Thomas and the Divinity of the Common Good", ob. cit. Se refiere alli al pasaje de Quaestiones de quolibet, 1.4.3 ed. Leonine, t. 25-2, Rome\Paris, 1996: Commissio Leonina \Cerf, [Pascua de 1269, según Weisheipl]: "Se dice, por consiguiente, que el amor a Dios sobre todas las cosas, [incluso] más que a uno mismo, es natural, no simplemente para el ángel o el ser humano, sino también para toda criatura sin más, en la medida en que es posible amar tanto sensible como naturalmente. Porque las inclinaciones naturales pueden ser conocidas más que nada en aquellas cosas que actúan naturalmente sin deliberación de la razón: porque en la naturaleza cada cosa actúa en tanto que tiene aptitud natural para actuar. Ahora bien, vemos que cada parte opera para el bien del todo a causa de una inclinación natural, incluso aceptando el peligro o detrimento para sí misma: como es evidente cuando alguien expone la mano a la espada con el fin de defender la cabeza de la cual depende la seguridad del cuerpo entero. Por consiguiente, es natural que cada parte, cualquiera que sea, en su propio nivel, ame más el todo que a sí misma. De ahí que, en función de esta inclinación natural y en función de la virtud politica, el buen ciudadano, por causa del bien común, se exponga a sí mismo al peligro de 
en función de esta finalidad suprema: promover condiciones sociales que coadyuven a que cada ser humano pueda alcanzar libremente la meta definitiva de su existencia, a saber, llegar a la plena comunión de amistad con Dios. Comunión que, a su vez, es condición de posibilidad de relaciones auténticamente fraternas. Así, el orden racional contenido en la ley natural, accesible a todo hombre, señala unas pautas ético-políticas fundamentales tanto para los ciudadanos como para los gobernantes. Recordemos la insistencia con que Santo Tomás deposita en el legislador la responsabilidad primordial de desarrollar en los ciudadanos las virtudes éticas. De hecho, remarca Dewan, "Es una enseñanza constante de Tomás de Aquino que el fin, la meta o el bien de la sociedad politica es la virtud, es decir, el bien humano, y que para lograr esto es necesario que los gobernadores sean virtuosos." 116

Y ser virtuoso no es más que seguir fielmente la voz de la naturaleza racional que nos inclina a la consecución de su telos o fin o bien propio. La consumación de nuestro ser individual y social no se alcanzará jamás si se desatiende dicha voz. Nuestro propósito al mostrar el valor decisivo de la vida social y del bien común para la plenitud humana, se encamina a evidenciar que resultados tan anhelados como son los de una convivencia justa y pacífica no podrán alcanzarse si no se atiende a estos elementos fundamentales de la vida individual y comunitaria. Tal como ha enseñado Lawrence Dewan, la naturaleza humana, obra de la divina sabiduría, marca el camino por seguir si queremos establecer relaciones justas, cuyo fruto es la paz.

\section{BibLIOGRAFÍA}

Aristóteles, Ética Nicomaquea, trad. J. Palli Bonet, Madrid, Gredos, 1993.

Aristóteles, Física, trad. G. de Echandía, Madrid, Gredos, 1995.

ARIstóteles, Metafisica, trad. T. Calvo Martínez, Madrid, Gredos, 1994.

Aristóteles, Partes de los animales, trad. Elvira Jiménez Sánchez-Escariche y Almudena Alonso Miguel, Madrid, Gredos, 2000.

BeHE, Michael J., "The Sterility of Darwinism”, Boston Review, February / March, 1997.

Dewan, Lawrence, Fundamentos metafisicos de la ética, trad. de L. Irizar, E. Carreño y J. J.Gómez, L., Bogotá, Fondo de Publicaciones de la Universidad Sergio Arboleda, 2009.

muerte. Ahora bien, es evidente que Dios es el bien común del universo entero y de todas sus partes. Por tanto, cualquier criatura, sin distinción, en su propio nivel, ama naturalmente a Dios más que a sí misma: [así sucede] con las cosas que carecen naturalmente de sentido, los brutos, y la criatura racional que [lo hace] a través del amor electivo, el cual en latín [a veces] es llamado 'dilectio"'.

116 Lawrence Dewan, Wisdom, Law and Virtue..., ob. cit., p. 286. Sobre el particular véase, por ejemplo, ST, 1-2.92.1, ad 3. 
Dewan, Lawrence, "Jacques Maritain and the Philosophy of Co-operation”, en M. Gourgues y G-D Mailhiot (eds.), Alterité. Vivre ensemble differents, Montral y Paris, Bellarmin/Cerf, 109-117, 1986.

Dewan, Lawrence, "La sabiduria y la vida humana: lo natural y lo sobrenatural", Actas del III Simposio Internacional fe cristiana y cultura contemporánea "Idea cristiana del hombre”, Pamplona, Eunsa, en http://dspace.unav.es/dspace/handle/10171/2779, 2002.

Dewan, Lawrence, "St. Thomas and the Divinity of the Common Good", Symposium in Honor to Russell Hittinger, Providence College, Rhode Island, 25-26 de abril de 2008.

Dewan, Lawrence, "St. Thomas and Metaphyscial Hierarchy: Some Observations", conferencia leída en el 42 Congress on Medieval Studies, Kalamazoo, 2007 (inédita).

Dewan, Lawrence, “St. Thomas's 'Fifth Way' Revisited”, Universitas, Taipei, 31, March, 2004, 3.

Dewan, Lawrence, “The Divine Origine of Law”, Civilizar, 8, 2008, 15.

Dewan, Lawrence, Wisdom, Law and Virtue. Essays in Thomistic Ethics, New York, Fordham University Press, 2008.

Tomás de Aguino, Comentario a la Física de Aristóteles, trad. Celina A. Lértora, Pamplona, Eunsa, 2001.

Tomás de Aguino, Comentario a la Politica de Aristóteles, trad. de Ana Mallea, Pamplona, Eunsa, 2001.

Tomás de Aguino, Comentario de la Ética a Nicómaco de Aristóteles, trad. A. Mallea, Pamplona, Eunsa, 2001.

Tomás DE Aguino, "Cuestión disputada sobre el bien”, en Opúsculos y obras selectas, trad. y anotaciones por una comisión de los PP. Dominicos presidida por A. Osuna Fernández-Largo O. P., Madrid, BAC, 2001.

Tomás DE Aguino, "Cuestión Disputada sobre las criaturas espirituales”, en A. Osuna Fernández-Lago (coord.), Opúsculos y Cuestiones Selectas, Madrid, BAC, 2001.

Tomás de Aguino, In librum B. Dionysii De divinis nominibus expositio, Rome \Turin, Marietti, 1950.

Tomás DE Aguino, Quaestiones de quolibet, ed. Leonine, t. 25-2, Rome \Paris, Commissio Leonina \Cerf., 1996. 
Tomás de Aguino, Suma contra gentiles, edición bilingüe dirigida por L. Robles Caicedo, O. P. y A. López Sierra, O. P., Madrid, BAC, 2007.

Tomás de Aguino, Suma Teológica, texto latino de la edición crítica Leonina, trad. y anotaciones por una comisión de los PP. Dominicos presidida por F. Barbado Viejo O. P., Madrid, BAC, 1954-1960.

Gilson, Étienne, De Aristóteles a Darwin (y vuelta), trad. A. Clavería, Pamplona, Eunsa, 1980.

Gilson, Étienne y Maritain, Jacques, Correspondance, 1923-1971, Géry Prouvost, (ed.), París, Vrin, 1991.

Gilson, Étienne y Maritain, Jacques, "St. Thomas and the Divinity of the Common Good”, Symposium in Honor to Russell Hittinger, Providence College, Rhode Island, 25-26 de abril de 2008.

IRIZAR, Liliana, Tras las huellas del sentido. Sabiduría y felicidad en Lawrence Dewan, Fundación Konrad Adenauer, Corporación Pensamiento Siglo XXI, Universidad Sergio Arboleda, 2008.

West, Jason L., Theocentric Natural Law: Reflections on Fr. Dewan's Ethics. Conferencia inédita presentada en the Canadian Society of Christian Philosophers Session in Honor to Lawrence Dewan, Congress of the Humanities and Social Sciences, Carleton University, Ottawa, 27 de mayo de 2009. 